\title{
The Antioxidant Role of Artichoke (Cynara scolymus L.) Extract Against Exhaustive Exercise-Induced Oxidative Stress in Young Athletes
}

\author{
Atashak S (Ph.D.) ${ }^{1}$ \\ 1- Department of exercise physiology, Mahabad Branch, Islamic Azad University, \\ Mahabad, Iran \\ *Corresponding author: Associate Professor of Exercise Physiology, Department \\ of Physical Education \& Sports Science, Azad University, Mahabad Branch, \\ University Street, Mahabad, Iran \\ Tel: +98 - 914 - 3180386; fax: +98 - 442 - 2233000. \\ E-mail: s.atashak@iau-mahabad.ac.ir
}

Received: 25 Dec. 2017

Accepted: 3 Dec. 2018 doi: 10.29252/jmp.3.71.37

\begin{abstract}
Background: Strenuous acute exercise induces oxidative stress in the active muscles and circulation, However, consumption of products rich in antioxidants may potentially ameliorate these effects.
\end{abstract}

Objective: The present investigation was conducted to determine the effect of Artichoke (Cynara scolymus $\mathrm{L}_{\text {.) }}$ extract on oxidative stress and antioxidant defense after aerobic exercise in young athletes.

Method: Twenty two subjects received $2400 \mathrm{ml} / \mathrm{kg} / \mathrm{day}$ Artichoke-leaf extract or placebo capsule for a period of 14 days. All subjects of both groups underwent in acute aerobic exercise before and after 14 days supplementation. Blood samples were collected at pre supplementation, pre exercise, post exercise and 24 hours after exercise. Malondiadehyde (MDA), plasma total antioxidant capacity (FRAP), superoxide dismutase (SOD), and 8-iso-prostaglandin-F2 $\alpha$ (8-isoPGF2 $\alpha$ ) were measured.

Results: The results showed that concentration of MDA and Serum 8-iso-PG F2 $\alpha$, SOD, and plasma total antioxidant significantly increased at immediately and $24 \mathrm{hrs}$ after aerobic exercise $(\mathbf{P}<0.05)$. Artichoke supplementation has no effect on concentration of MDA, FRAP and SOD activity immediately after aerobic exercise (P>0.05), but after 24-h of exercise, 8-iso-PG F2 $\alpha$ concentration in the group supplement was significantly lower in comparison to placebo group $(\mathrm{P}=\mathbf{0 . 0 0 2})$.

Conclusion: The results of this study indicated that a single session of strenuous aerobic exercise induces oxidative stress production and increase of antioxidant indices in young athletes. However, further studies are necessary to clarify the exact antioxidant effects of Artichoke extract in athletes.

Keywords: Total antioxidant capacity, Malondiadehyde, Superoxide dismutase, 8-isoprostaglandin-F2 $\alpha$, Medicinal plants 


\section{Introduction}

Despite the fact that regular exercise training is associated with numerous positive physiological adaptations, and consequently with numerous health benefits (including prevention of cardiovascular disease, diabetes, cancer, hypertension, obesity, depression, osteoporosis and premature death) [1-3], strenuous acute exercise induces oxidative stress in the active muscles and circulation [4]. It is plausible that oxygen consumption level and metabolic rate considerably increase during exercise (high intensity and/ or long duration moderate) [5], and this may, in turn, lead to an elevation of superoxide anion production in the mitochondria and increase oxidative stress [6], a state where increased generation of ROS overwhelms body antioxidant protection and subsequently induces lipid, protein and DNA damage [7] and it is thought that play an important role in the pathophysiology of this disease [8]. Moreover, it seems that in sports and exercise training, oxidative stress can implicated in muscle damage [7] and development of symptoms of overtraining including increased fatigue, decreased immune function and decreased performance [5, 9-10].

Nevertheless, all aerobic organisms, including human beings, have antioxidant defenses that protect against oxidative stress damages. However, this natural antioxidant mechanism may be inefficient during strenuous exercise, hence, many of investigators and clinicians in an attempt to attenuate the oxidative stress biomarkers [11], which, it has been suggested that exerciseinduced oxidative stress may reduce by supplementation with antioxidants. Antioxidants are substances that help reduce the severity of oxidative stress either by forming a less active radical or by quenching the reaction [12]. In this regards, recently, the use of herbal antioxidants, because of fewer side effects than synthetic antioxidant component, more has been attention from several researchers [13].

Artichoke (Cynara scolymus L.) is one of the famous traditional medicinal plants that found mainly in the Mediterranean countries [14]. Artichoke (Cynara scolymus L.) is an ancient herbaceous plant that has been used for many years in traditional medicine for various types of therapeutic conditions such as hepatoprotective, antimicrobial and hypolipidemic [15]. There are also some reports in the literature for antioxidant effects of Artichoke leaf extracts [16], which it has been found that Artichoke decrease the production of reactive oxygen species, and oxidative stress indices such as lipid peroxidation and protein oxidation [15], moreover this herbal supplement increase the activity of glutathione peroxidase as antioxidant enzyme [17].

According to consumption of Artichoke (Cynara scolymus L.) may be beneficial in ameliorating the negative effects of oxidative stress damage following strenuous aerobic exercise, hence, the present investigation was conducted to determine whether graded maximal aerobic would elevate post exercise oxidative stress biomarkers. Specifically, we tested the hypothesis that aqueous extract of Artichoke (Cynara scolymus L.) can attenuate exercise-induced oxidative stress in young athletes after graded maximal aerobic exercise. 


\section{Materials and Methods}

\section{Participants and Study design}

In a randomized double-blind placebocontrolled trial, twenty four active men were allocated into two equal groups: supplement $(n=11)$ and placebo $(n=11)$ groups. The criteria of exclusion were cardiovascular and pulmonary disease, smoking, obesity and hormonal abnormalities. Moreover, none of them was taking exogenous anabolic-androgenic steroids, drugs, medication, or dietary supplements with potential on redox and physical performance during six months preceding the study. The experimental procedures and potential risks were explained, and informed consent was obtained from all subjects. All were asked to abstain from intense physical activity for $48-72 \mathrm{~h}$ before the measurements. The study protocol and methodology, in accordance with the Declaration of Helsinki, were approved by the Clinical Research Ethics Committee of the Mahabad Islamic Azad University of Iran and were and conducted in a laboratory environment (temperature 22 - $25 \mathrm{C}^{\circ}$; humidity 50-55\%). Physical and physiological characteristics of the subjects at the beginning of the research are presented in Table 1. 30810/7809

There were no differences between groups at the beginning of the research for age, $\mathrm{VO}_{2} \max$, body weight, height, and BMI and body fat percent $(\mathrm{P}>0.05)$.

\section{Anthropometric and Physiological Measurements}

Subjects' height (nearest $0.1 \mathrm{~cm}$ ) and weight (nearest $0.1 \mathrm{~kg}$ ) were measured using a stadiometer and digital scale, and BMI (body weight $[\mathrm{kg}] /$ height $\left[\mathrm{m}^{2}\right]$ ) was calculated. Fat density (fat mass) was predicted from the skinfold measurements taken on the right side of the body using a specialised skin fold caliper (Baseline Dconomy 'Slim-Guide') at the triceps, abdominal, and super iliac sites after $10 \mathrm{~h}$ of fasting. Percentage body fat was then estimated through regression equations described by Brozek, et al. [18]. Moreover, one week before the study protocol the maximal oxygen uptake or $\mathrm{VO}_{2}$ max of each subject was estimated from a maximal multistage 20-m shuttle run test [19].

\section{Supplementation protocol}

The supplemented group was given two Artischocken capsules (each capsule contained $400 \mathrm{mg}$ of Artichoke (Cynara scolymus L.), product EuRho Vital, Germany, Which consisted of the following compounds; Artichoke-Concentrate (79.7 g), Gelatine of Cow, Water, Bulking Agent Magnesium Stearate, Colouring E) tree times per day (2400 $\mathrm{mg} /$ day), for fourteen days, and the control group received a placebo of the same form and size at the same times. During supplementation, all subjects completed a validated food intake questionnaire and recorded a 24 hours food record to determine if both groups had similar diets. All subjects reported adherence to the experimental protocol and complete ingestion of the supplement. 
The Antioxidant Role ...

Table 1- Physical and Physiological characteristics of the supplement and placebo groups

\begin{tabular}{lccc}
\hline & Supplementation $(\mathbf{n}=11)$ & Placebo $(\mathbf{n}=11)$ & P \\
\hline Age $($ year $)$ & $24.18 \pm 3.11$ & $23.03 \pm 2.55$ & 0.359 \\
Height $(\mathrm{cm})$ & $176.29 \pm 5.11$ & $175.53 \pm 6.71$ & 0.721 \\
Weight $(\mathrm{kg})$ & $76.49 \pm 8.13$ & $73.64 \pm 6.41$ & 0.294 \\
BMI $(\mathrm{kg} / \mathrm{m} 2)$ & $24.61 \pm 2.1$ & $23.90 \pm 1.76$ & 0.442 \\
Body fat $(\%)$ & $18.11 \pm 2.96$ & $16.93 \pm 3.19$ & 0.241 \\
VO2 max $(\mathrm{ml} / \mathrm{kg} / \mathrm{min})$ & $44.65 \pm 4.39$ & $45.82 \pm 3.94$ & 0.311 \\
\hline
\end{tabular}

Values are mean \pm standard deviation

\section{Exercise test}

One week prior to initiation of the study protocol, all participants visited the laboratory to familiarize them to the experimental exercise test (separate to the $\mathrm{VO}_{2} \max$ ). The subjects performed a gentle warm-up before beginning a multistage $20-\mathrm{m}$ shuttle run test. The shuttle run test was carried out on flat terrain between two parallel lines $20 \mathrm{~m}$ apart, and required continuous running with progressive intensity. The test ended when the participant failed to come within $2 \mathrm{~m}$ of the ends of the lines at the moment indicated by the tape. The maximal aerobic exercise protocol utilized in this study has been reported previously [20]. Each subject performed exactly the same exercise test on a second occasion, just after the end of the fourteen day intervention period; this being the experimental exercise test.

\section{Blood collection and analysis procedures}

Blood samples were collected prior to supplementation for baseline analysis of oxidative stress biomarkers. Further samples were taken pre-exercise, immediately postexercise and $24 \mathrm{hrs}$ following the experimental exercise test. A $5 \mathrm{~mL}$ blood sample was extracted via venipuncture of an antecubital vein and collected into a specialized blood tube ( $5 \mathrm{ml}$; made by SUHA Co); the resultant samples were allowed to clot at room temperature for $10 \mathrm{~min}$ and then centrifuged for $15 \mathrm{~min}$ at $0{ }^{\circ} \mathrm{C}$. The serum was then pipetted into polystyrene tubes and frozen at $-80{ }^{\circ} \mathrm{C}$ for subsequent analysis. The total antioxidant capacity of plasma was evaluated by applying the FRAP assay (ferric reducing antioxidant power or ferric reducing ability of plasma) according to the method of Benzie and Strain (1996) [21]. The method is based on the reduction of ferric $\left(\mathrm{Fe}^{3+}\right)$ to ferrous $\left(\mathrm{Fe}^{2+}\right)$ ion at low $\mathrm{pH}$. This causes a formation of blue colored ferrous tripyridyltriazine $\left(\mathrm{Fe}^{2+}\right.$ TPTZ) complex, which absorbs at $593 \mathrm{~nm}$. Moreover, plasma malondialdehyde (MDA) concentrations spectrophotometrically were assayed by measurement of thiobarbituric acid reactive substances (TBARS) assay according to the procedure of Uchiyama and Mihara (1978) [22]. Serum 8-iso-PG F2 $\alpha$ levels were measured in duplicate using an enzyme immunoassay kit (Cayman Chemicals Co., Ann Arbor, Michigan, USA) [23]. Moreover, the activity of superoxide dismutase (SOD) was measured at $500 \mathrm{~nm}$ with a commercially available kit (Randox Laboratories, kit Ransod superoxide dismutase).

\section{Statistical analyses}

All data were tested for homogeneity of variance and for normal distribution using a Kolmogorov-Smirnov and Levene's test 
before statistical procedures were applied. The differences in physiological characteristics of the subjects in two groups at the beginning of the research were performed using independent $t$ test. Two-way repeated measures ANOVAs with 2 groups (Artichoke supplementation and placebo) and 4 time points (pre supplementation, pre exercise, post exercise and 24 hours after exercise) for plasma malondialdehyde, FRAP, SOD and serum 8-iso-PG F2 $\alpha$ across the assessment protocol. For all analyses, the level of significance was $\mathrm{P}<0.05$. All results shown are mean $\pm \mathrm{SD}$ in the text, figures and tables.

\section{Results}

Results demonstrated no significant difference between activity of SOD, Serum 8iso-PG F2 $\alpha$, and also FRAP and MDA plasma in supplement and placebo before starting the study protocol $(\mathrm{P}>0.05)$. Results also showed that concentrations of MDA significantly increased immediately post-exercise and $24 \mathrm{hrs}$ after aerobic exercise in both supplement and placebo groups $(\mathrm{P}<0.05)$. However, there were no differences in the pattern of change between groups (group effect, $\mathrm{P}=0.657$ ) (Fig. 1).

The changes in FRAP and SOD levels following aerobic exercise, as shown in Fig. 2 and Fig. 3, indicated that these antioxidant biomarkers increased significantly after the aerobic exercise in both groups $(\mathrm{P}<0.05)$, but there were no differences in the pattern of change between supplement and placebo groups (group effect, $\mathrm{P}=0.279$ and $\mathrm{P}=0.172$ respectively). On the other hand, acute exercise would result in an increase in oxidative stress biomarkers in both conditions.

Interestingly, the serum concentration of 8iso-PG F $2 \alpha$, as a measure of oxidative stress, increased significantly immediately postexercise and $24 \mathrm{hrs}$ after aerobic exercise in both supplement and placebo groups $(\mathrm{P}<0.05)$, but the pattern of change in the 8-iso-PG F2 $\alpha$ was significantly higher $24 \mathrm{~h}$ post exercise in placebo versus supplement group $(\mathrm{P}=0.002)$, as well as exhibiting interaction $(\mathrm{P}=0.000)$ and time $(\mathrm{P}=0.001)$ effects (Fig. 4).

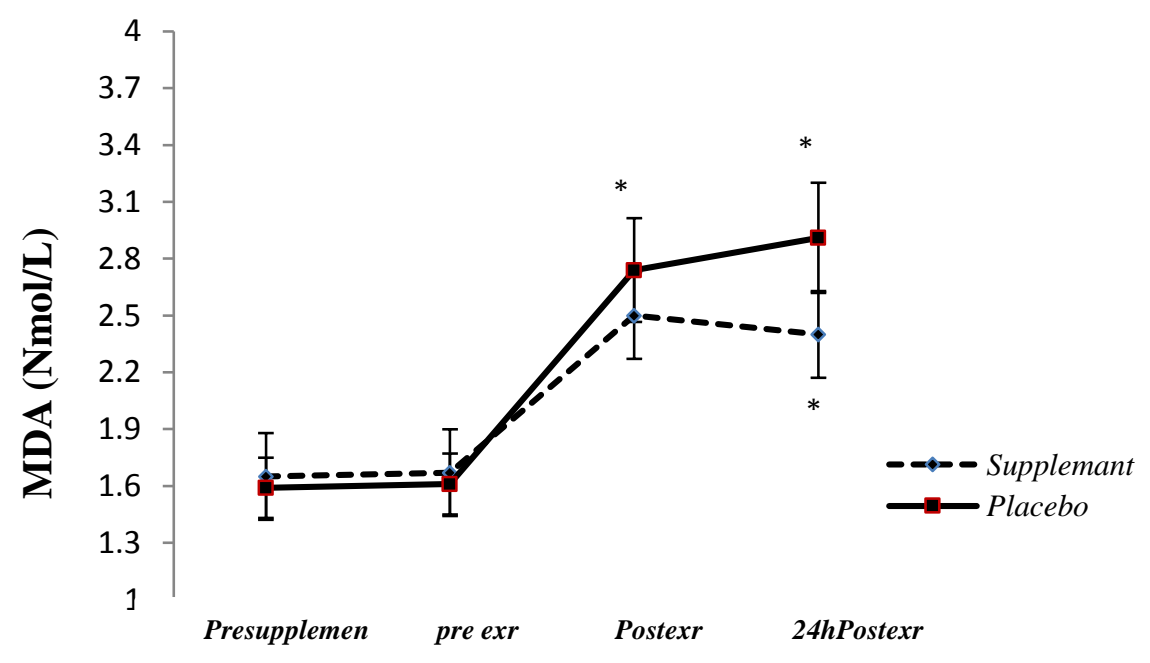

Fig. 1- Plasma malondialdehyde (MDA) concentration at pre supplementation, Pre exercise, Post exercise and 24 hours after exercise, * Indicate Significant difference $(P<0.05)$ compared with Presupplement and pre exercise. 
The Antioxidant Role ...

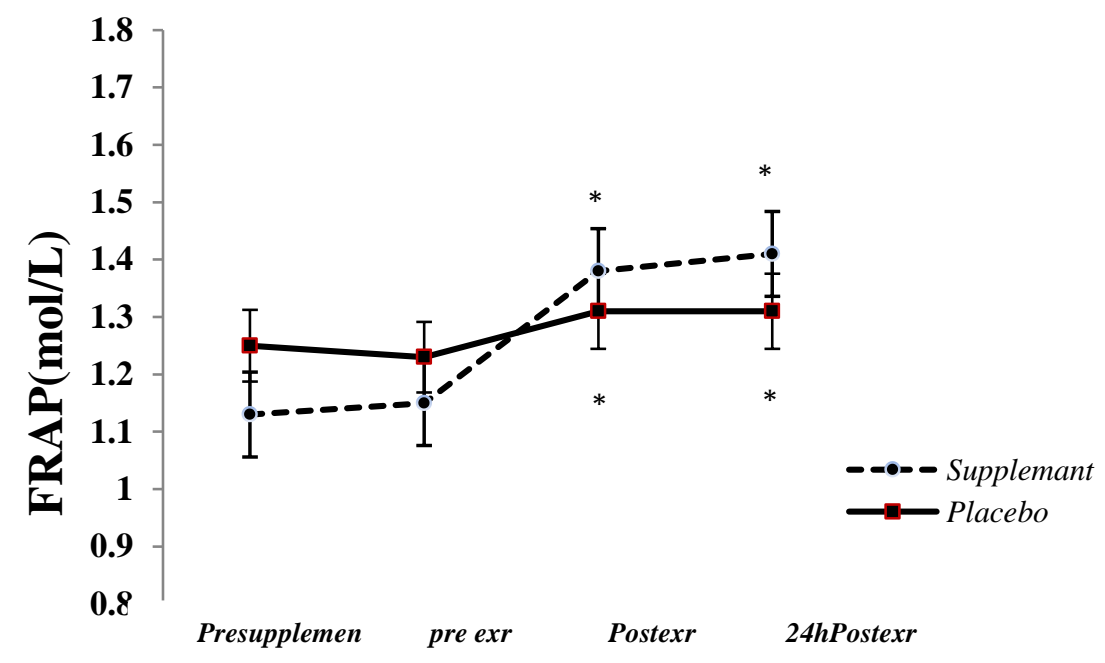

Fig 2- Plasma total antioxidant capacity of plasma (FRAP) concentration at pre supplementation, Pre exercise, Post exercise and 24 hours after exercise

* Indicate Significant difference $(\mathbf{P}<0.05)$ compared with Presupplement and pre exercise.

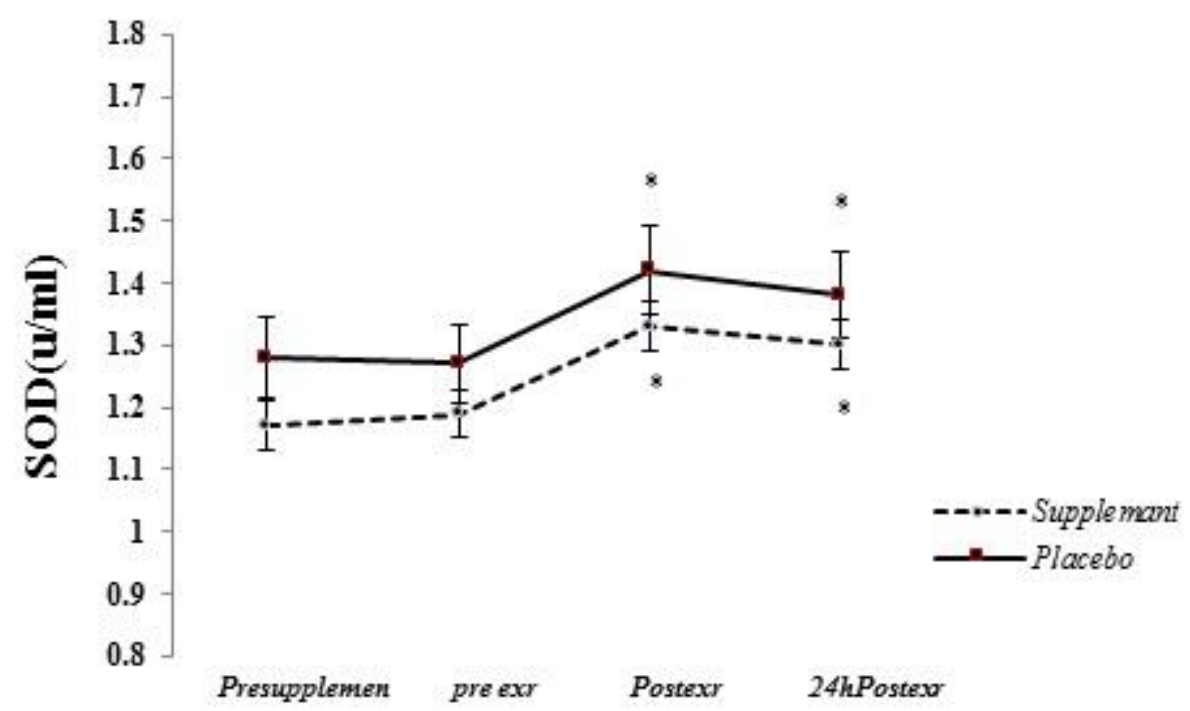

Fig. 3- Superoxide Dismutase (SOD) activity at pre supplementation, Pre exercise, Post exercise and 24 hours after exercise

* Indicate Significant difference $(\mathbf{P}<0.05)$ compared with Presupplement and preexr. 


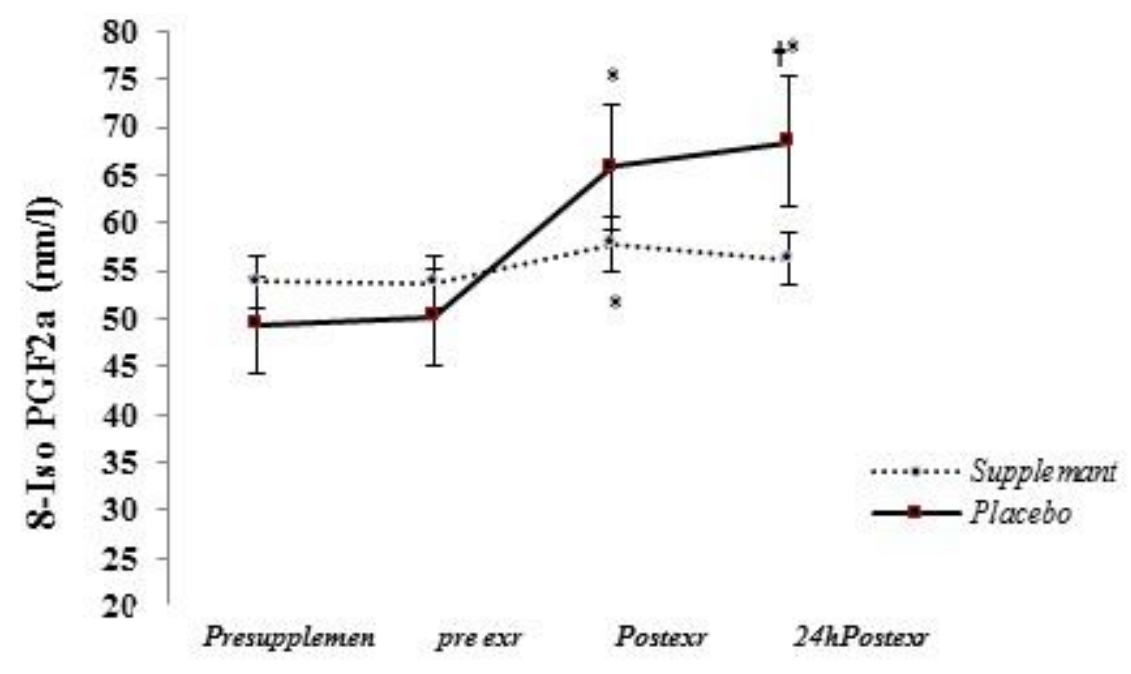

Fig. 4- Serum 8-iso-PG F2 $\alpha$ concentration at pre supplementation, Pre exercise, Post and 24 hours after exercise. * Indicate Significant difference $(\mathbf{P}<0.05)$ compared with Presupplement and pre exercise.

\section{Discussion}

While is well established that regular exercise training is associated with a numerous health benefits, some published studies indicate that strenuous exercise leads to increased oxidative cellular damage and decreased muscle performance. However, consumption of products rich in antioxidants may potentially ameliorate these effects. Therefore, this study was conducted to investigate the effects of Artichoke (Cynara scolymus L.) extract on oxidative stress and antioxidant defense in young athletes after graded maximal aerobic exercise.

The first finding of this study is that maximal aerobic exercise induces a measureable increase in oxidative stress and antioxidant biomarkers. In accordance with the results of this study, recently it has been shown that exhaustive aerobic exercise induces a significant rise in the oxidative stress markers malondialdehyde and lipid hydroperoxides in healthy male subjects.
Researchers attributed this increase in cell membrane oxidation to a greater production of free radicals and subsequent attack on membrane phospholipids [24]. In this context, Waring et al. reported that plasma 8-isoPGF $2 \alpha$ concentrations, a measure of lipid peroxidation, significantly increased following high-intensity aerobic exercise [25]. Furthermore, it has been suggested that exercise intensity and duration plays a major role in post-exercise blood oxidative stress; very high intensity exercise appears to exaggerate this stress response [26]. Johnson et al. revealed that exercise-induced thiobarbituric acid reactive substances (TBARS), as an index of oxidative stress, were exercise intensity-dependent, which significantly increased following acute aerobic exercise at $80 \%$ VO (2peak) versus $50 \%$ $\mathrm{VO}_{2}$ peak in trained men [27]. In this regard, Fisher-Wellman and bloomer, in their review, reported that during low-intensity and duration protocols, antioxidant defenses appear 
sufficient to meet the RONS production, but as intensity and/or duration of exercise increases, these defenses are no longer adequate, potentially resulting in oxidative damage to surrounding tissues [9]. It has been proposed that, aerobic exercise through two mechanisms might result in increase of oxidative stress [1]: 1) increased pro-oxidant activity via a mass action effect when $\mathrm{VO}_{2}$ is elevated 10- to 15 fold above rest; and 2) inadequate antioxidant activity relative to pro-oxidants [28]. Furthermore, because of the increase in oxygen consumption by mitochondria during exercise, there is an increase in free radical formation by these organelles [29].

It has also been shown that acute exercise is followed by an increase in antioxidant enzyme activity in plasma and other tissues [30]. For example Diaz et al. demonstrated that total antioxidant capacity (TAC) and superoxide disumutase (SOD) activity significantly increased immediately after aerobic exercise in young adults (Bruce-protocol treadmill test to $75-80 \%$ of their heart rate reserve) [31]. It seems that exercise activates different redoxsensitive transcription factors, including NF$\kappa \mathrm{B}$, probably through the induction of free radicals generated by the exercise [32].

Results of some previous studies are in contrast to our findings. Saritas et al. observed that acute aerobic exercise (12 min run test) had no effect on plasma antioxidant capacity and markers of DNA damage in young trained men [33]. Moreover, others have shown that a $20 \mathrm{~km}$ running race did not significantly influence on TBARS, (index of lipid peroxidation), in trained male athletes [34]. The differences in the exercise intensity /or training status, participant's age and body status may account for the discrepancy between our results may account for the discrepancy between studies.

It has been suggested that antioxidant supplementation can attenuate exerciseinduced oxidative stress. In this regard, the use of herbal antioxidants after physical exercise has received attention from several researchers. For example, SkarpańskaStejnborn et al. reported that black grape extract supplementation significantly increased plasma antioxidant capacity and superoxide dismutase activity, and therefore, may attenuate blood oxidative stress in response to acute exercise in male rowers [35]. It was also indicated that short-term blackcurrant extract consumption might result in attenuation of exercise-induced oxidative stress in healthy subject [36]. On this basis, the therapeutic benefits of Artichoke (Cynara scolymus L.) were used in the present study to test the hypothesis that this herb would reduce exercise-induced oxidative stress. In support of our hypothesis, it had been revealed that administration of Artichoke extract prevents of oxidative stress-induced hepatotoxicity by decrease hepatic MDA and increase of antioxidant levels in rats [14]. ZapolskaDownar et al. demonstratet that artichoke extracts have marked protective properties against oxidative stress induced by inflammatory mediators and ox-LDL in cultured endothelial cells and monocytes [37]. The potential probably mechanism by Artichoke may reduce the harmful effects of free radicals and oxidative stress could be related to their antioxidant compounds. In this 
regard, it has been reported that the antioxidant properties of Artichoke result from its high content of chlorogenic acid, cynarine, and flavonoid- derivatives of luteoline [38]. Moreover Skarpañska-Stejnborn et al. reported that Artichoke (Cynara scolymus L.), as a natural vegetable preparation of high antioxidant potential, significantly increased total antioxidant capacity in competitive rowers subjected to strenuous training [39]. $\mathrm{Li}$ et al. also reported that flavonoids from artichoke (Cynara scolymus L.) up-regulate endothelial-type nitric-oxide (NO) synthase gene expression in human endothelial cells [40], and interestingly it has been proposed that, NO can protect against oxidative damage by intercepting reactive species, which converting them to less damaging and more easily detoxified products [41]. While in contrast to our results these researches also indicated that supplementation with Artichoke did not influence the level of free radicaldamage markers. The difference in dosage can explain this difference. However, there is a dearth of published data available in support of this finding, and thus the exact mechanism which underpins our finding is unknown. Clearly, further studies are necessary to affirm the antioxidant properties and oxidative stressscavenging of Artichoke (Cynara scolymus L.) extract in athletes and the mechanism through which this is affected.

\section{Conclusion}

In conclusion, the results of the present research indicate that a single session of strenuous aerobic exercise induces oxidative stress, but also an increase of antioxidant activity in the circulation of young athletes. However, fourteen days supplementation with Artichoke (Cynara scolymus L.) extract may ameliorate the exercise induced increase in serum iso-PG F2 $\alpha$ concentrations $24 \mathrm{hrs}$ after acute aerobic exercise, suggesting a protective effect of the herb on oxidative damage.

\section{Acknowledgment}

We would like to thank our participants in our study. Also, we would like to appreciate the President of Research, Islamic Azad University, Mahabad Branch, for providing financial support for the present study.

\section{Conflicts of interest:}

The authors declare that they have no conflicts of interest concerning for this article.

\section{References}

1. Belviran $M$ and Gökbel H. Acute exercise induced oxidative stress and antioxidant changes. Eur. J. Gen. Med. 2006; 3: 126-31.

2. Thirumalai T, Therasa SV, Elumalai EK and David E. Intense and exhaustive exercise induce oxidative stress in skeletal muscle. Asian Pac. J. Trop. Dis. 2011; 1: 63-6.
3. Melzer K, Kayser B and Pichard C. Physical activity: the health benefits outweigh the risks. Curr. Opin. Clin. Nutr. Metab. Care 2004; 7: 641-7.

4. Fatouros IG, Jamurtas AZ, Viliotou V, Pouliopoulou S, Fotinakis P, Taxildaris K and Deliconstantinos G. Oxidative stress responses in older men during endurance training and 
detraining. Med. Sci. Sports Exerc. 2004; 36: 2065-72.

5. Djordjevic D, Cubrilo D, Macura M, Barudzic N, Djuric D and Jakovljevic V. The influence of training status on oxidative stress in young male handball players. Mol. Cell. Biochem. 2011; 351: 251-9.

6. Davies K, Quintanilha A, Brooks A and Packer L. Free radical and tissue damage produced by exercise. Biochem. Biophys. Res. Commun. 1982; 107: 1198-205.

7. Sen CK, Packer $L$ and Hanninen O. Handbook of oxidants and antioxidants in exercise. Elsevier, Amsterdam, 2000.

8. Araujo MC, Soares FS, Ronsani MM, Rocha LG, Vieira LC, Silva LA. Lycopene supplementation attenuates oxidative stress parameters in the plasma of humans with CVD after Intense Exercise. Food Nutr. Sci. 2001; 2: 241-8.

9. Fisher-Wellman K, Bloomer RJ. Acute exercise and oxidative stress: a 30 year history. Dynamic Medicine 2009; 8: 1-25.

10. Tanskanen M, Atalay $M$ and Uusitalo A. Altered oxidative stress in overtrained athletes. J. Sports Sci. 2010; 28: 309-17.

11. Bloomer RJ, Canale RE, Blankenship MM and Fisher-Wellman KH. Effect of Ambrotose $\mathrm{AO}$ on resting and exercise-induced antioxidant capacity and oxidative stress in healthy adults. Nutr. J. 2010; 9: 49: 2-17.

12. Shan $X$, Zhou J, Ma $T$ and Chai $Q$. Lycium barbarum Polysaccharides reduce exercise-induced oxidative stress. Int. J. Mol. Sci. 2011; 12: 1081-8.

13. Atashak S, Piree M, Azarbayejani MA, Stannard SR and Haghighi MM. Obesityrelated cardiovascular risk factors after long- term resistance training and ginger supplementation. J. Sports Sci. Med. 2011; 10: 685-91.

14. Mehmetcik G, Ozdemirler G, KocakToker N, Cevikbas U and Uysal M. Effect of pretreatment with artichoke extract on carbon tetrachloride-induced liver injury and oxidative stress. Exp. Toxicol. Pathol. 2008; 60: 475-80.

15. Rangboo V, Noroozi M, Zavoshy R, Rezadoost SM and Mohammadpooras A. The Effect of Artichoke Leaf Extract on Alanine Aminotransferase and Aspartate Aminotransferase in the Patients with Nonalcoholic Steatohepatitis. Int. J. Hepatol. 2016; ID 4030476, 6 pages http://dx.doi.org/10.1155/2016/4030476.

16. Wang M, Simon JE, Aviles IF, He K, Zheng QY and Tadmor Y. Analysis of antioxidative phenolic compounds in artichoke (Cynara scolymus L.). J. Agric. Food Chem. 2003; 51: 601-8.

17. Jimenez-Escrig A, Dragsted LO, Daneshvar B, Pulido R and Saura-Calixto F. In vitro antioxidant activities of edible artichoke (Cynara scolymus L.) and effect on biomarkers of antioxidants in rats. J. Agric. Food Chem. 2013; 51 (18): 5540-5.

18. Brozek J, Grande F, Anderson $T$ and Keys A. Densitometric analysis of body composition: Revision of some quantitative assumptions. Ann. N. Y. Acad. Sci. 1963; 26: 113-40.

19. Leger LA and Lambert J. A maximal multistage 20-m shuttle run test to predict VO2 max. Eur. J. Appl. Physiol. Occup. Physiol. 1982; 49: 1-12.

20. Atashak $\mathrm{S}$ and Jafari A. Effect of shortterm creatine monohydrate supplementation on 
indirect markers of cellular damage in young soccer players. Sci. \& Sports 2012; 27: 88-93.

21. Benzie IFF, Strain JJ. Ferric reducing ability of plasma (FRAP) as a measure of antioxidant power: The FRAP assay. Anal. Biochem. 1996; 239: 70-6.

22. Uchiyama $\mathrm{M}$ and Mihara $\mathrm{M}$. Determination of malondialdehyde precursor in tissues by thiobarbituric acid test. Anal. Biochem. 1978; 86: 271-8.

23. Roberts CK, Won D, Pruthi S, Kurtovic S, Sindhu RK, Vaziri ND and Barnard J. Effect of a short-term diet and exercise intervention on oxidative stress, inflammation, MMP-9 and monocyte chemotactic activity in men with metabolic syndrome factors. J. Appl. Physiol. 2006; 100: 1657-65.

24. Fogarty MC, Hughes CM, Burke $G$, Brown J, Trinick TR, Duly E, Bailey DM and Davison GW. Exercise-induced lipid peroxidation: implications for deoxyribonucleic acid (DNA) damage and systemic free radical production. Environ. Mol. Mutagen. 2011; 52: 35-42.

25. Waring WS, Convery A, Mishra V, Shenkin A, Webb DJ and Maxwell SRJ. Uric acid reduces exercise-induced oxidative stress in healthy adults. Clin. Sci. 2003; 105: 425-30.

26. Quindry JC, Stone WL, King $\mathrm{J}$ and Broeder CE. The effects of acute exercise on neutrophils and plasma oxidative stress. Med. Sci. Sports Exerc. 2003; 35: 1139-45.

27. Johnson BD, Padilla $J$ and Wallace JP. The exercise dose affects oxidative stress and brachial artery flow-mediated dilation in trained men. Eur. J. Appl. Physiol. 2012; 112: 33-42.
28. Alessio HM, Hagerman AE, Fulkerson BK, Ambrose J, Rice RE and Wiley RL. Generation of reactive oxygen species after exhaustive aerobic and isometric exercise. Med. Sci. Sports Exerc. 2000; 32: 1576-81.

29. Gomez-Cabrera MC, Domenech E and Vina J. Moderate exercise is an antioxidant: upregulation of antioxidant genes by training. Free Radic. Biol. Med. 2008; 44: 126-31.

30. Berzosa C, Cebri'an I, Fuentes-Broto L, Trullen EG, Piedrafita E, Balların EM, LopezPingarron M, Reiter RG and Garcia JJ. Acute exercise increases plasma total antioxidant status and antioxidant enzyme activities in untrained men. J. Biomed. Biotechnol. 2011; 1-7.

31. Diaz KM, Feairheller DL, Sturgeon KM, Williamson ST and Brown MD. Oxidative stress response to short duration bout of submaximal aerobic exercise in healthy young adults. Int. J. Exerc. Sci. 2011; 4: 247-56.

32. Gomez-Cabrera MC, Borrás C, Pallardo FV, Sastre J, Ji LL and Viña J. Decreasing xanthine oxidase-mediated oxidative stress prevents useful cellular adaptations to exercise in rats. J. Physiol. 2005; 567: 113-20.

33. Saritas N, Uyanik F, Hamurcu $Z$ and Çoksevim B. Effects of acute twelve minute run test on oxidative stress and antioxidant enzyme activities. Afr. J. Pharm. Pharmacol. 2011; 5: 1218-22.

34. Kele M, Sermet A, Atmaca M and Kocyigit Y. Changes in blood antioxidant status and lipid peroxidation following distance running. Int. J. Med. Sci. 1998; 28: 643-7.

35. Skarpańska-Stejnborn A, Basta P, Pilaczyńska-Szcześniak $€$ and HoroszkiewiczHassan M. Black grape extract supplementation 
attenuates blood oxidative stress in response to acute exercise. Biol. Sport 2010; 27: 41-6.

36. Lyall KL, Hurst SM, Cooney J, Jensen D, Lo D, Hurst RD and Stevenson LM. Short-term blackcurrant extract consumption modulates exercise-induced oxidative stress and lipopolysaccharide-stimulated inflammatory responses. American J. Physiol. 2009; 297: 70-81. 37. Zapolska-Downar D, Zapolski-Downar A, Naruszewicz M, Siennicka A, Krasnodebska B and Kołdziej B. Protective properties of artichoke (Cynara scolymus) against oxidative stress induced in cultured endothelial cells and monocytes. Life Sci. 2002; 71 (24): 2897-908.

38. Llorach R, Espin JC, Tomas-Barberan FA and Ferreres F. Artichoke (Cynara scolymus L.) byproducts as a potential source of healthpromoting antioxidant phenolics. J. Agric. Food
Chem. 2002; 50 (12): 3458-64.

39. Skarpañska-Stejnborn A, PilaczynskaSzczesniak L, Basta P, Deskur-Smielecka E and Horoszkiewicz-Hassan M. The influence of supplementation with artichoke (Cynara scolymus L.) extract on selected redox parameters in rowers. Int. J. Sport Nutr. Exerc. Metab. 2008; 18: 313-27.

40. Wink DA and Peter CF. Nitric oxide reactions important to biological systems: a survey of some kinetics investigations. Methods 1995; 7 (1): 14-20.

41. Li H, Xia N, Brausch, Yao $Y$ and Förstermann U. Flavonoids from artichoke (Cynara scolymus L.) up-regulate endothelialtype nitric-oxide synthase gene expression in human endothelial cells. J. Pharmacol. Exp. Ther. 2004; 310 (3): 926-32. 